(20-24 September, www.sccs-bng.org) and the USA (11-13 October 2017, bit.ly/SCCS-New-York).

Christina Nicole De Jesus Villanueva Department of Biological Sciences, University of Rhode Island, Kingston, Rhode Island, USA

E-mail christinadejesusvillanueva@gmail.com

Clatre Louise Stewart School of Biological Sciences, University of Queensland, Brisbane, Queensland, Australia E-mail clairestewart2703@gmail.com

\section{8th International Conservation Forum for Arabia's Biodiversity}

The 18th Annual Sharjah International Conservation Forum for Arabia's Biodiversity was held at the Breeding Centre for Endangered Arabian Wildlife in Sharjah, United Arab Emirates, during 6-9 February 2017. The Forum brought together over 180 participants from Jordan, Kuwait, Lebanon, Bahrain, UAE, Saudi Arabia, Oman and Afghanistan, and also from the UK, South Africa, Italy, Netherlands, USA and New Zealand. The Sharjah workshops are hosted by the Environment and Protected Areas Authority of the Government of Sharjah, under the patronage of H.H. Sheikh Dr Sultan bin Mohammed al Qasimi, Member of the Supreme Council and Ruler of Sharjah.

The 18th meeting had four themes. A species assessment theme conducted an IUCN Red List assessment of the trees and aloes of the Arabian region. The protected areas theme evaluated the management of selected protected areas in the region. The veterinary theme looked at issues around ruminant parasite examination and treatment, and nutritional requirements for wildlife. The Forum also supported the first regional planning meeting for conservation of vultures, held under the auspices of the Convention on Migratory Species.

Working groups conducted a regional Red List assessment for all the endemic trees and aloes of the Arabian region. In total, 308 species were assessed, comprising 50 aloes (all endemic), and 186 tree species on the Arabian Peninsula and a further 72 tree species endemic to the island of Socotra. The analysis of changes in protected area management effectiveness of selected sites between 2009 and 2017 concluded there had been some improvements. In addition, participants trialled the use of an expanded Management Effectiveness Tracking Tool currently used in South Africa, concluding that a modified version of this could be appropriate for use in the Arabian region.

The veterinary theme's main focus was nutrition and endoparasite control of herbivores. An emphasis was placed on using nutritional software to compile optimal diets for grazers and for the browsers in captivity. Component analysis of diets currently being used in the region was identified as a critical matter that needs to be addressed. The question of whether or not to drench wildlife for endoparasites was discussed at length, and it was agreed it is necessary to look at these endoparasites as symbiotic organisms that live inside hosts.

PHILIP SEDDON Department of Zoology, University of Otago, Dunedin, New Zealand

E-mail philip.seddon@otago.ac.nz

MIKE KNIGHT South African National Parks, \& Centre for African Conservation Ecology, Nelson Mandela Metropolitan University, Port Elizabeth, South Africa

Gerhard SteENKAmp Department of Companion Animal Clinical Studies, Faculty of Veterinary Science, University of Pretoria, Ondeserspoort, South Africa

Craig Hilton-Taylor IUCN Red List Unit, Cambridge, UK

DAVID MALLON Manchester Metropolitan University, UK, \& IUCN/Species Survival Commission Conservation Planning Sub-Committee 